\title{
Investigation of Solar Drying of Ginger (Zingiber officinale): Emprical Modelling, Drying Characteristics, and Quality Study
}

\author{
A. Waheed Deshmukh, ${ }^{1,2}$ Mahesh N. Varma, ${ }^{2}$ Chang Kyoo Yoo, ${ }^{3}$ and Kailas L. Wasewar ${ }^{2,3}$ \\ ${ }^{1}$ Priyadarshini Institute of Engineering and Technology, RTMN University, Nagpur, Maharashtra 440018, India \\ ${ }^{2}$ Advanced Separations and Analytical Laboratory, Department of Chemical Engineering, \\ Visvesvaraya National Institute of Technology (VNIT), Nagpur, Maharashtra 440011, India \\ ${ }^{3}$ Environmental Management \& Systems Engineering Lab (EMSEL), Department of Environmental Science and Engineering, \\ College of Engineering, Kyung Hee University, Seocheon-dong 1, Giheung-gu, Yongin-Si, Gyeonggi-Do 446-701, Republic of Korea
}

Correspondence should be addressed to Kailas L. Wasewar; k_wasewar@rediffmail.com

Received 13 December 2013; Accepted 9 February 2014; Published 13 March 2014

Academic Editors: Z. Li and I. Ortiz

Copyright (C) 2014 A. Waheed Deshmukh et al. This is an open access article distributed under the Creative Commons Attribution License, which permits unrestricted use, distribution, and reproduction in any medium, provided the original work is properly cited.

\begin{abstract}
Drying is a simultaneous heat and mass transfer energy intensive operation, widely used as a food preservation technique. In view of improper postharvest methods, energy constraint, and environmental impact of conventional drying methods, solar drying could be a practical, economical, and environmentally reliable alternative. In the present paper applicability of mixed mode solar cabinet dryer was investigated for drying of commercially important and export oriented ginger. Freshly harvested ginger slices were successfully dried from initial moisture content of 621.50 to $12.19 \%$ (d.b.) and their drying characteristics, quality parameters, and kinetics were evaluated. The results showed that present solar dryer could be successfully applied for drying of ginger in view of quality, reduced drying time, and zero energy requirement as compared to conventional open sun drying and convective drying techniques, respectively. Drying curves showed that drying occurred in falling rate period and no constant period was observed. The effective moisture diffusivity was determined by using Fick's second law and found to be $1.789 \times 10^{-9} \mathrm{~m}^{2} / \mathrm{s}$. The drying data was fitted to five thin layer drying models and compared using statistical criteria. Page model was found to be most suitable to describe the drying kinetics of ginger in solar dryer under natural convection among the tested models.
\end{abstract}

\section{Introduction}

Drying has a vital role in postharvest processing. It has always been of great importance for conserving agricultural products and for extending the food shelf life [1]. Many of the moisture-mediated deterioration reactions and reproduction of micro-organisms causing decay can be prevented by removal of moisture by appropriate drying method. However limited resources of fossil fuels and extensive usage are responsible for adverse effects on environment and also economic viability. Open sun drying of various crops is the most widespread conventional method for food preservation practiced in many urban and rural areas of developing countries. The major disadvantage of this technique is low quality and hygienic problems of the product. The product gets contaminated from dust, insects, rodents, and other animals which seriously degrade the food quality and ultimately results in a negative trade potential and economical worth. Labor requirement, long drying time (2-3 days), and direct exposure of the produce to sun and wind are the further difficulties with this method. In order to ensure continuous food supply to growing population and to enable the farmers to produce high quality marketable products, efficient and at the same time affordable drying methods are necessary. Varieties of mechanical energy driven dryers are available for preventing the deterioration of products and to reduce the drying time. These conventional dryers and drying techniques are not economical due to high energy cost [2]. Commercially various energy based drying techniques such as forced convective drying, fluidized bed drying, heat pump drying, microwave drying, freeze drying, and many more are available and widely practiced. Diminishing reserves of fossil fuels and 
increased cost have made drying as an energetically expensive and unaffordable technique for farmers. Studies have shown that even small and most simple oil-fired batch dryers are not applicable for most farmers, due to lack of capital investment and insufficient supply of energy for the operation of dryers. Therefore the introduction of low cost and locally manufactured solar dryers can offer a promising alternative to reduce the tremendous postharvest losses. The opportunity to produce high quality marketable products seems to be a chance to improve the economic situation of the farmers. However, taking into account the low income of the rural population, the relatively high investment for energy based dryers still remains a barrier to wide application. In view of this, solar dryers can be a good alternative over conventional dryers and open sun drying technique. Solar energy is free, abundant, environmentally clean, and therefore is recognized as one of the most promising alternative energy. In near future, the large-scale introduction of solar energy systems, directly converting solar radiation into heat, can be looked forward [3]. Moderate amounts of fuel wood or fossil fuels currently used in developing countries for the process of food and crop can be replaced by proper use of solar drying technologies [4]. The climatic conditions in India are good with about 300 clear and sunny days and theoretical solar power reception, on its land area, is about 5 trillion $\mathrm{kWh} /$ year. The daily average solar energy incident over India varies from 5 to $7 \mathrm{kWh} / \mathrm{m}^{2}$ with about 1500-2000 sunshine hours per year depending upon location, which is far more than current energy consumption [5]. The study carried out by Chavda and Kumar [6] indicates that cost of drying with solar power is only one-third as compared to the cost using a dryer based on conventional fuels. These solar dryers allow for controlled drying by managing the drying parameters such as moisture content, air temperature, humidity, and air flow rate. Adequate drying helps to preserve the flavor, texture, and color of the food, which leads to a better quality product [7]. Thus solar dryers are more economical as compared to other dryers if properly employed. Appropriate use of solar drying has significant potential, especially in agricultural areas which suffer from a high proportion of postharvest losses through food spoilage.

Ginger is an important spice cash crop of the world. It is one of the earliest known oriental spices and is being cultivated in India for both as fresh vegetable and as a dried spice. Ginger is obtained from the rhizomes of Zingiber officinale. The ginger family is a tropical group, especially abundant in Indo-Malaysian region, consisting of more than 1200 plant spices in 53 genera. The area under the cultivation in India is 108.6 thousands hectors and the total production of the country is 517.8 thousand tons [8]. Ginger and its products have varied applications in culinary preparation, bakery products, toiletry products, perfume industries, meat products, wine, and soft drinks making. Dried ginger is used both as a spice and medicine. It contains an essential oil, which imparts an aroma, an oleoresin responsible for the pungent smell, starch, gums, proteins, carbohydrate, mineral matter, and fiber [8]. In Ayurveda, it is termed as an important medicine to cure many diseases, such as rheumatism, piles, dyspepsia, alcoholic gastritis, fabric disease, throat problems, cholera morbus, neuralgia, and pulmonary and catarrhal diseases. It is expected that the world demand of ginger will double in the next five years [9]. The quality of ginger produced in India has high content of aroma and pungency and it is also organic. But due to improper postharvest processing most of the ginger is to be consumed as a fresh vegetable and also some of the good qualities such as visual appeal, texture, aroma, flavor, structure, and color of the material get affected.

Several studies have been reported on a variety of solar dryers for drying different fruits, vegetables, and grains [16]. Few of them are amaranth [17], seed pumpkin [18], sweet pepper and garlic [19], tomato seed [20], grape [21], pineapple [22], fig and onion [23], sour cherry [24], date palm [25], mango slices [26], and so forth. Design of different types of solar dryer has been reported by Phoeun et al. [27]. It includes design of solar cabinet dryers, solar box dryers, tunnel dryers, and solar tray dryers for rural farmers. Although various attempts have been made to study the solar drying of various agricultural products, very few works are reported on the solar drying of ginger and effect on quality parameters, particularly in mixed mode solar cabinet dryer. In view of this, the present study was undertaken to assess the applicability of mixed mode solar cabinet dryer for drying of ginger. This study includes the investigation of drying characteristics, kinetics, effective diffusivity, and evaluation of some quality parameters of ginger in solar drying system. The experimental drying data was fitted to five mathematical models available in the literature and best suited model for predicting drying kinetics of ginger was determined among the tested models.

\section{Material and Methods}

2.1. Experimental Setup. A mixed mode box-cabinet natural circulation solar dryer was developed for the present study as shown in Figure 1. The dryer consists of a primary solar collector $(1 \times 0.5) \mathrm{m}$. A transparent sheet was located over the collector. The fresh air was sucked and heated through the air duct and flows to the drying chamber. A secondary solar collector $(0.75 \times 0.5) \mathrm{m}$ oriented north-south was covered with a single layer of $0.15 \times 10^{-6}$ thick UV stabilized polyethylene film and hinged at the top of the drying chamber. It allows the solar radiations to drying chamber and further enhances the drying rate by greenhouse effect. The drying chamber was coated with black paint, thermally insulated with asbestos sheets to minimize the heat loss provided with the support for sample holding mesh trays having area $1 \mathrm{~m}^{2}$. The general rule of thumb is that $1 \mathrm{~m}^{2}$ of tray area is needed to layout $10 \mathrm{~kg}$ of produce. The air is warmed up during its flow through a low pressure drop thermosyphonic primary solar collector. The moisture is removed by natural convection and greenhouse effect by secondary solar collector in drying chamber. The moist air is then discharged through the air vents provided at the top of the drying chamber. Drying studies in solar cabinet dryer were conducted with two replicates. Accurately weighted ginger slices ( $5 \mathrm{~kg}$ per batch) of initial moisture content $621.5 \%$ d.b. were evenly distributed on the sample holding mesh trays. After predetermined time 


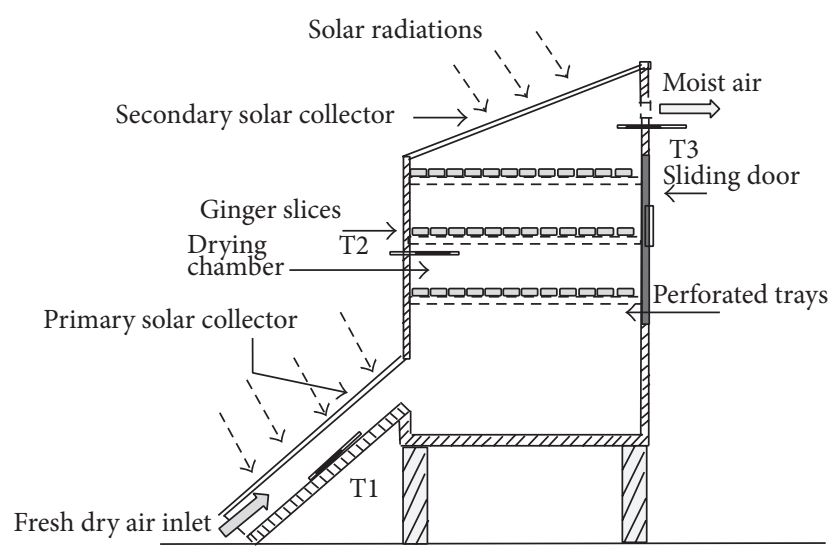

FIGURE 1: Mixed mode box-cabinet natural circulation solar dryer.

interval reduction of weight of material was noted by using Electronic Weighing balance (Wensar Ltd. India, HPB 310, least count $0.1 \mathrm{gm}$ ). The temperature of the air was monitored at primary solar collector, drying chamber, and at the exit of drying chamber by PT-100 sensor thermocouples with accuracy of $\pm 0.5^{\circ} \mathrm{C}$ at regular time intervals.

2.2. Sample Preparations. Fresh ginger was purchased from local market of Nagpur, India, and washed thoroughly to remove surface dust and extraneous matter under running water. The clean ginger was hand peeled by knife and cut into thin slices of average thickness of $6 \pm 0.5 \mathrm{~mm}$. The slices were kept at ambient for one hour to remove surface moisture. The initial moisture content of fresh ginger was determined by hot air oven drying method [28]. Accurately weighed sample $(100 \mathrm{gm})$ of ginger was placed in a laboratory oven at the constant temperature of $60^{\circ} \mathrm{C}$ until the constant weight was achieved. Five replications were taken and average value was calculated on dry basis by following equations.

Moisture content on dry basis (\% d.b.)

$$
M_{\text {initial }}=\frac{W_{w}-W_{d}}{W_{d}} \times 100,
$$

where $M_{\text {initial }}$ is the initial moisture content of ginger on d.b. $\%, W_{w}$ is the wet weight, and $W_{d}$ is the dry weight of ginger in $\mathrm{kg}$.

Drying Rate. The drying rates at different timing during solar drying were computed in all experimental conditions using following relationship [29]:

$$
\frac{d M}{d T}=\frac{M_{o}-M_{t}}{t},
$$

where $d M / d t$ is drying rate ( $\mathrm{kg}$ water $/ \mathrm{kg}$ of material. min), $t$ is time ( $\mathrm{min}$ ), and $M_{o}$ and $M_{t}$ are the initial and final moisture content, respectively.

Effective Diffusivity. Drying process in falling rate period for food materials is mostly governed by diffusion mechanism [1]. Fick's second diffusion law has been widely used to
TABLE 1: Thin layer drying models applied to drying data of ginger.

\begin{tabular}{lcc}
\hline Model name & Model equation & References \\
\hline Newton & $\mathrm{MR}=\exp (-k t)$ & {$[10,11]$} \\
Page & $\mathrm{MR}=\exp \left(-k t^{n}\right)$ & {$[12]$} \\
Modified Page & $\mathrm{MR}=\exp \left[(-k t)^{n}\right]$ & {$[13]$} \\
Henderson and Pabis & $\mathrm{MR}=a \exp (-k t)$ & {$[14]$} \\
Wang and Sing & $\mathrm{MR}=1+a t+b t^{2}$ & {$[15]$} \\
\hline
\end{tabular}

describe the moisture removal in falling rate periods. The effective diffusivity of the material can be calculated by assuming constant moisture diffusivity, temperature, and negligible shrinkage during drying process using the following equation:

$$
\ln \mathrm{MR}=\ln \left(\frac{8}{\pi^{2}}\right)-\frac{\pi^{2} D_{\mathrm{eff}} t}{L^{2}},
$$

where $D_{\text {eff }}$ is the effective diffusivity, $L$ is the half of the thickness of ginger slice in meter, and $t$ is the corresponding drying time in sec. The Effective diffusivity can be calculated by plotting experimental $\ln (\mathrm{MR})$ versus drying time, gives a straight line with slope of:

$$
\text { Slope }=\frac{\pi^{2} D_{\text {eff }}}{L^{2}}
$$

Mathematical Modeling of Drying Data. Thin layer drying procedure is generally practiced for characterizing the drying parameters [30]. The empirical models present the direct relationship between the average moisture content and drying time by means of regression analysis, neglecting the fundamental of drying process. Full scale experimentation of dehydration processes for different products is not economically feasible; hence, employing the simulation model for drying rate predication may be an easy and valuable tool [31]. To select a suitable model for describing the drying process of ginger, experimental results were fitted to various thin layer drying models which are summarized in Table 1 . The moisture ratio of ginger during the drying was calculated by using the following equation:

$$
\mathrm{MR}=\frac{M_{t}-M_{e}}{M_{o}-M_{e}},
$$

where $M_{t}, M_{o}$, and $M_{e}$ are the moisture content on dry basis at any time, initial, and equilibrium, respectively. The value of dynamic equilibrium moisture content is relatively small as compared to $M_{t}$ and $M_{o}$, hence the error involved in the simplification is negligible [32], and hence moisture ratio was calculated as

$$
\mathrm{MR}=\frac{M_{t}}{M_{o}}
$$

Suitability of the best model was determined by statistical criteria, namely, coefficient of determination $\left(R^{2}\right)$, reduced 
chi-square $\left(\chi^{2}\right)$, root mean square error (RMSE), and percent relative error described as [23]:

$$
\begin{gathered}
\chi^{2}=\frac{\sum_{i=1}^{N}\left(\mathrm{MR}_{\text {exp }, i}-\mathrm{MR}_{\mathrm{pre}, i}\right)^{2}}{N-n} \\
\mathrm{RMSE}=\frac{1}{N}\left[\frac{\sum_{i=1}^{N}\left(\mathrm{MR}_{\mathrm{exp}, i}-\mathrm{MR}_{\mathrm{pre}, i}\right)^{2}}{N}\right]^{1 / 2} \\
\varepsilon(\%)=\left|\frac{\left(\mathrm{MR}_{\mathrm{pre}, i}-\mathrm{MR}_{\mathrm{exp}, i}\right)}{\mathrm{MR}_{\text {exp }, i}} \times 100\right|,
\end{gathered}
$$

where $\mathrm{MR}_{\exp , i}$ and $\mathrm{MR}_{\text {pre }, i}$ are the experimental and predicted moisture ratio for the same measurement, respectively. $N$ is the number of observation and $n$ is the number of constants in drying model. The best model was chosen as the one with higher coefficient of determination, least reduced chi square, root mean square error, and percent relative error [33].

Rehydration Study. Rehydration study was carried out by adding $3 \mathrm{gm}$ of dried ginger in $100 \mathrm{~mL}$ distilled water at room temperature $\left(34 \pm 1^{\circ} \mathrm{C}\right)$ the samples were weighed at a regular time interval until the constant weight was achieved by the sample. After rehydration, samples were taken out; surface moisture was absorbed carefully with tissue paper and then weighed. The rehydration capacity was calculated as follows [10]:

$$
\text { Rehydration capacity }=\frac{W_{r}}{W_{d}} \text {, }
$$

where $W_{r}$ is the weight after rehydration $\mathrm{kg}$ and $W_{d}$ is the weight of dried ginger $\mathrm{kg}$.

Color Analysis. Color analysis for fresh, open sun-dried, and solar-dried ginger sample was done on three randomly selected slices at 10 different locations. The color of both samples was determined by using Chromameter CR-400 (Minolta, Japan). Three parameters for the dried samples, $L^{*}$ (lightness), $a^{*}$ (redness), and $b^{*}$ (yellowness), were used to study the changes in color. $L^{*}$ represent the lightness or darkness of the sample on the scale of 0-100 where white $=$ 100 and dark $=0$. Hunter $a^{*}$ represent redness $(+)$ or greenness $(-)$. Hunter $b^{*}$ represent yellowness $(+)$ or blueness $(-)$. The total color difference $(\Delta E)$ was determined using the following equations [34]:

$$
\begin{gathered}
\Delta E=\sqrt{\left(\Delta L^{*}\right)^{2}+\left(\Delta a^{*}\right)^{2}+\left(\Delta b^{*}\right)^{2}} \\
\Delta L^{*}=L^{*}-L_{o}^{*}, \quad \Delta a^{*}=a^{*}-a_{o}^{*}, \quad \Delta b^{*}=b^{*}-b_{o}^{*} .
\end{gathered}
$$

Higher value of $\Delta E$ indicates greater color change from reference material. $L_{o}^{*}, a_{o}^{*}$, and $b_{o}^{*}$ are the color parameters of fresh samples used as the reference.

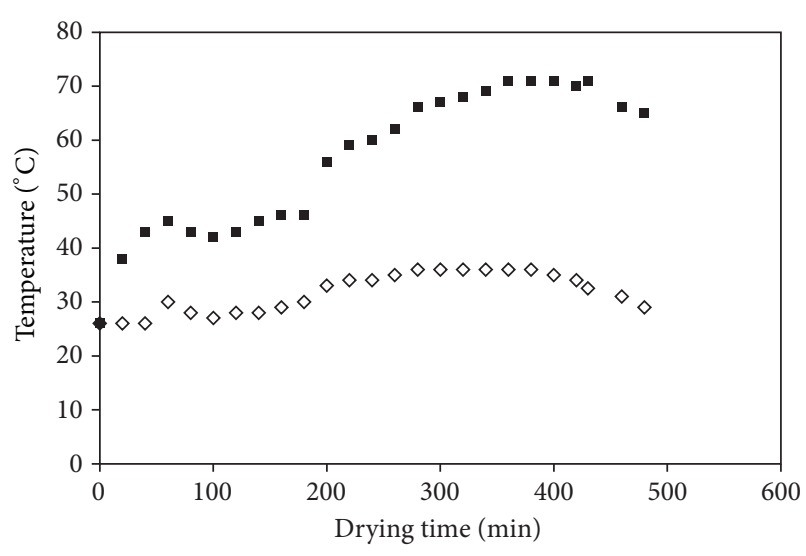

$\diamond$ Ambient temperature $(\text { mean }=31 \pm 4.5)^{\circ} \mathrm{C}$

- Temperature inside solar dryer (mean $57 \pm 8.5)^{\circ} \mathrm{C}$

Figure 2: Comparison of ambient and dryer temperature with drying time.

\section{Results and Discussion}

3.1. Drying Characteristics. Figure 2 compares the temperature developed inside the solar cabinet dryer and ambient temperature throughout the drying period. It was observed that the temperature developed in the dryer is always greater than the ambient temperature. The temperature in the drier varied between $38^{\circ} \mathrm{C}$ and $70^{\circ} \mathrm{C}$, and a considerable difference was observed between ambient and dryer temperature. The temperature in the dryer increases after $200 \mathrm{~min}$ (approximately 12 to $1 \mathrm{pm}$ ) remarkably, as the sun attained the highest position in the sky. The angle of insolation at this stage became closest to $90^{\circ}$, this leads to the intense solar radiations. The average temperature inside the dryer was found to be $57 \pm 8.5^{\circ} \mathrm{C}$. For most of the food materials the recommended drying temperature is $60-70^{\circ} \mathrm{C}$ [35]. This confirms that the present solar cabinet dryer can be effectively used for drying of agricultural product such as ginger. The drying curve for ginger slices is shown in Figure 3, where the moisture content decreases continuously with time. The drying rate was found to be faster initially, up to $200 \mathrm{~min}$. As the drying progressed, the drying rate decreased with time. It is typical drying behavior for agricultural materials reported by many researchers $[9,36]$. Ginger with initial moisture content $621.50 \%$ (d.b.) was successfully dried up to $12.19 \%$ (d.b.). The maximum drying period required for this was observed to be $480 \mathrm{~min}$ ( 8 hours) which is quiet less as compared to conventional open sun drying (2-3 days) [9].

As shown in Figure 4 drying rate decreases continuously with decreasing moisture content. This is due to high amount of free moisture availability, which was easily removed in the initial stage of drying [37]. The entire drying process was occurred in falling rate period and constant rate period was found to be absent in the present drying study. This is due to the fact that material surface is no longer saturated with water and drying rate is controlled by diffusion of moisture from interior of solid to the surface. It was also observed from Figure 5 that rate of drying shows fluctuations 


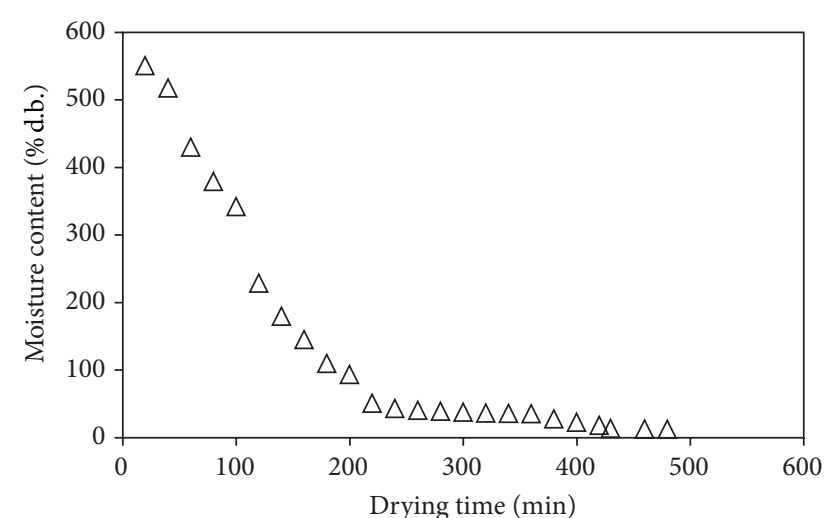

FIGURE 3: Variation of moisture content of ginger with drying time.

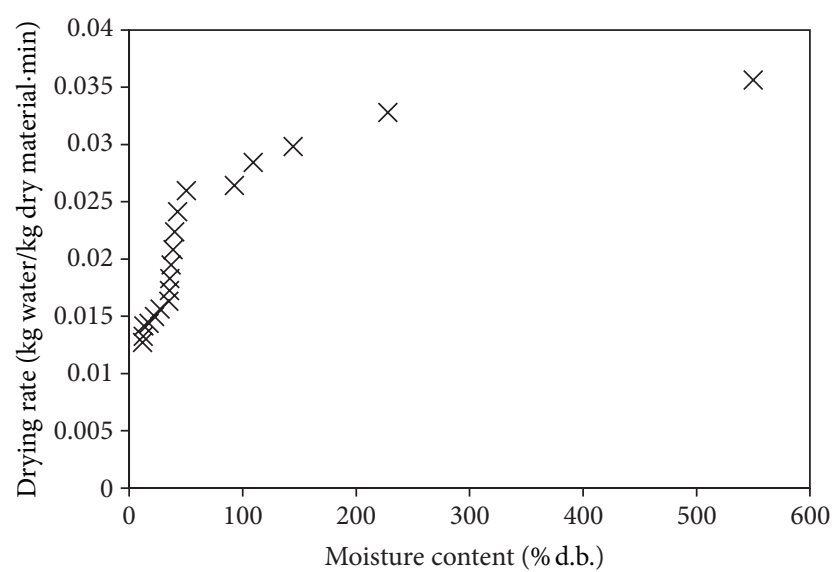

FIGURE 4: Variation of drying rate of ginger with moisture content.

at some instants and decreases with time. These fluctuations in the drying rate may be due to change in intensity of solar radiations falling on dryer. Hence drying rate will depend on moisture content as well as intensity of solar radiations. These results are in agreement with the observations of the earlier researchers based on the thin layer drying studies [17].

3.2. Effective Diffusivity. Present study reveals that drying mainly occurred in falling rate period. During the falling rate drying period the mass transfer is governed by internal resistance. In this case Fick's second law can be used to calculate effective diffusivity of the material. The effective diffusivity of the ginger in present solar dryer was calculated by plotting $\ln (\mathrm{MR})$ with drying time as shown in Figure 6 and using (3), where slope of the straight line gives the effective diffusivity of the sample. The effective diffusivity of the ginger slices in present solar dryer was found to be $1.789 \times 10^{-9} \mathrm{~m}^{2} / \mathrm{s}$ which is within the range of $10^{-9}$ to $10^{-11} \mathrm{~m}^{2} / \mathrm{s}$ reported in the literature for drying of food material.

3.3. Mathematical Modelling of Drying Data. The regression analysis was done for five selected models from Table 1 by relating the drying time and dimensionless moisture ratio. The suitability of the model was decided based on value of

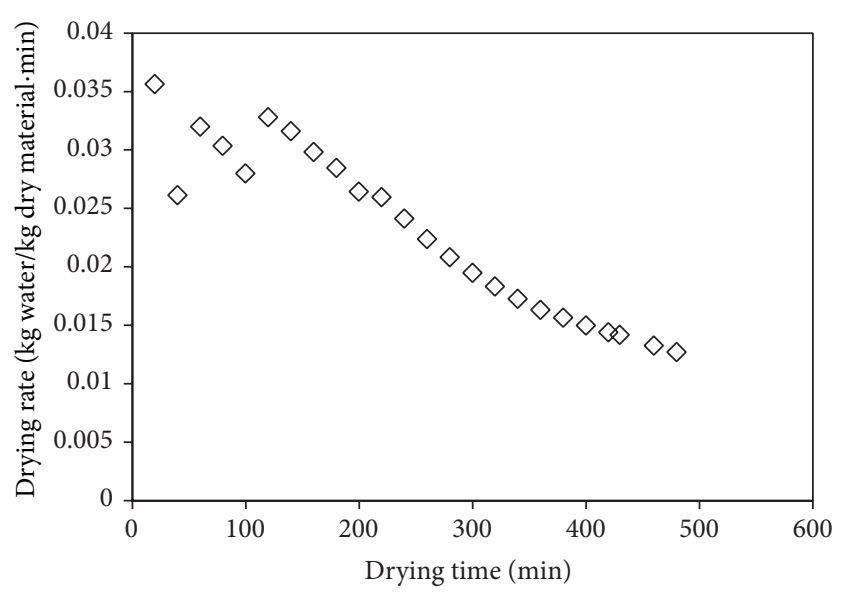

FIGURE 5: Variation of drying rate of ginger with drying time.

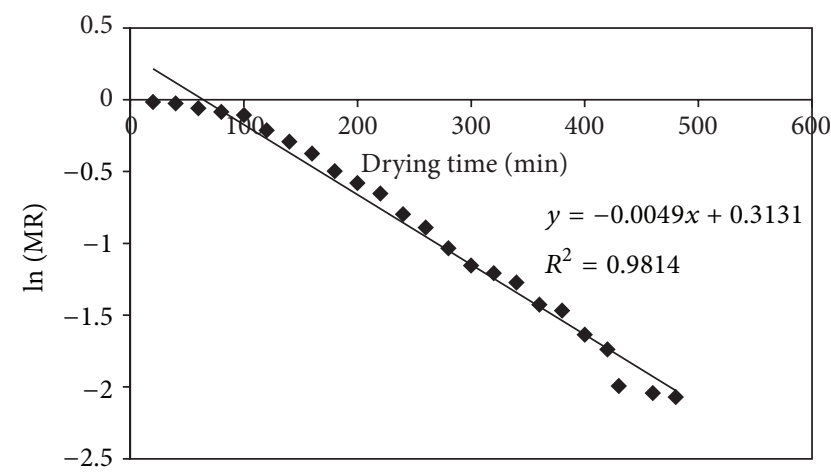

FIgURE 6: Plot of $\ln (\mathrm{MR})$ versus drying time for determination of effective diffusivity.

coefficient of determination $\left(R^{2}\right)$, should be close to one, low value of chi-square $\left(\chi^{2}\right)$, root mean square error (RMSE), and percent relative error [17]. The model coefficients and parameters are presented in Table 2. From regression analysis, it can be seen that the Page model satisfactorily describes the drying kinetics of the ginger with $R^{2}$ of $0.9823, \chi^{2}$ of 0.003 , RMSE of 0.0538 , and $\varepsilon$ (\%) of $1.78 \%$.

Figure 7 presents the variation of experimental and predicted moisture ratio using the Page model with drying time for ginger. It was observed the Page model shows the best agreement between experimental and predicted values of moisture ratio. The experimental moisture ratio was plotted against the predicted value of moisture ratio to validate the Page model as shown in Figure 8. The result showed smooth and scattered data points around the fitted line. This confirms the goodness of the tested developed model to estimate the moisture content of ginger in drying process for present solar dryer.

3.4. Quality Analysis. The success of any drying method lies on quality of product dried. Rehydration capacity and alteration in color are the major deciding parameters. The rehydration capacity and total color change index value, $\Delta E$ for solar and open sun-dried ginger, was calculated by using (10) 
TABLE 2: Statistical results and model coefficients obtained from selected thin layer drying models for solar cabinet drying of ginger.

\begin{tabular}{|c|c|c|c|c|c|c|}
\hline Model number & Model & $\begin{array}{l}\text { Model coefficients and } \\
\text { constants }\end{array}$ & $R^{2}$ & RMSE & $\chi^{2}$ & $\varepsilon(\%)$ \\
\hline 1 & Newton & $k=0.0039$ & 0.9269 & 1.008 & 0.0106 & 11.4 \\
\hline 2 & Page & $\begin{array}{c}k=0.0074 \\
n=1.675\end{array}$ & 0.9823 & 0.0538 & 0.003 & 1.78 \\
\hline 3 & Henderson and Pabis & $\begin{array}{c}k=0.0047 \\
a=1.305\end{array}$ & 0.9638 & 0.014 & 0.0049 & 5.27 \\
\hline 4 & Wang and Singh & $\begin{aligned} a & =-0.0025 \\
b & =1 \times 10^{-6}\end{aligned}$ & 0.946 & 0.0731 & 0.0058 & 6.83 \\
\hline 5 & Modified Page model & $\begin{array}{c}k=0.0034 \\
n=1.675\end{array}$ & 0.9753 & 0.055 & 0.0034 & 3.47 \\
\hline
\end{tabular}

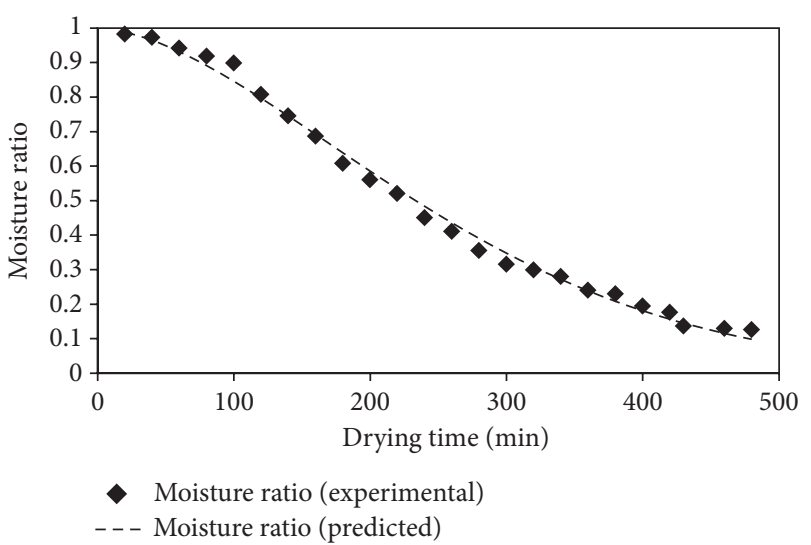

Figure 7: Comparison of experimental moisture and predicted moisture ratio with drying time by Page model.

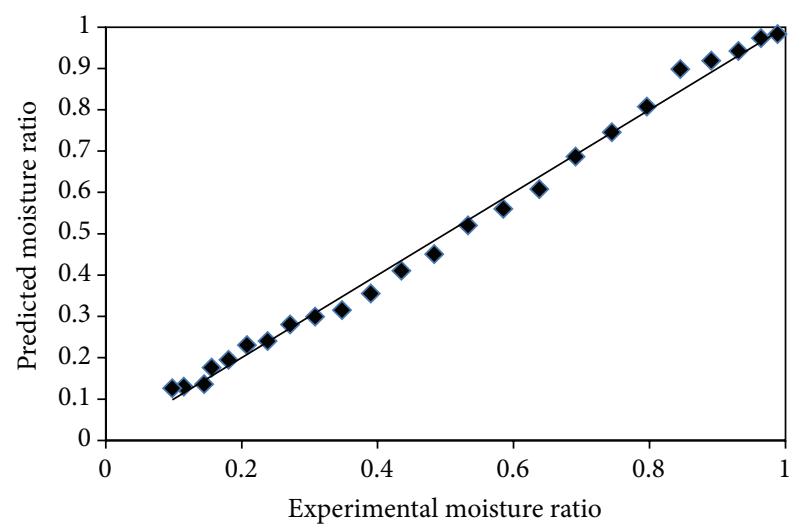

FIGURE 8: Comparison of experimental and predicted moisture ratio by Page model.

and (11), respectively. The results obtained show that solardried ginger yields a better quality in terms of color and rehydration capacity as compared to open sun drying. The $\Delta E$ and rehydration capacity was found to be $31.05,52.32$ and 3.65 and 2.12 for solar and open sun dried ginger, respectively. This confirmed the appropriate drying without considerable shrinkage and color and present solar drier gives better product quality as compared to open sun drying and quiet comparative to some other well developed techniques [11].

\section{Conclusion}

In the present study, solar cabinet dryer exhibited sufficient ability to dry ginger reasonably rapidly to a safe moisture level without any energy investment and positive environmental impact. Simultaneously it ensures a superior quality of the dried product over the conventional open sun drying method. The maximum drying time required to dry ginger from 621.50 to $12.19 \%$ (d.b.) was found to be 450 to 480 minutes. The drying time was found to be drying rate and moisture content dependent. Thin layer drying studies show that constant rate period is absent and the entire drying process occurred in falling rate period. The experimental drying data was fitted to five different mathematical models and compared using statistical criteria. Page model was found to be best suitable to describe the drying kinetics of ginger among the tested models. The moisture ratio obtained experimentally and predicted by Page model shows good agreement and fitted smoothly to straight line. The model attained the highest value of $R^{2}$, lowest value of $\chi^{2}$, and RMSE $\left(R^{2}, 0.9823, \chi^{2}, 0.003\right.$, RMSE, 0.0538). Lowest value of percent relative error $(\% \varepsilon, 1.78)$ further confirmed its superiority over the other models. In view of low capital investment, zero emission, and energy requirement as compared to other conventional drying methods the results confirmed the potential of solar cabinet dryer for drying of ginger and other agricultural products.

\section{Conflict of Interests}

The authors declare that they have no conflict of interests regarding the publication of this paper.

\section{References}

[1] I. Doymaz, "Air-drying characteristics of tomatoes," Journal of Food Engineering, vol. 78, no. 4, pp. 1291-1297, 2007.

[2] G. Gürlek, N. Özbalta, and A. Güngör, "Solar tunnel drying characteristics and mathematical modelling of tomato," Journal of Thermal Science and Technology, vol. 29, no. 1, pp. 15-23, 2009.

[3] L. M. Bal, S. Satya, and S. N. Naik, "Solar dryer with thermal energy storage systems for drying agricultural food products: a review," Renewable and Sustainable Energy Reviews, vol. 14, no. 8, pp. 2298-2314, 2010. 
[4] K. Sopian, A. Sayigh, and Y. Othman, "Solar assisted drying systems innovative technologies for agricultural and marine products," Publications of The Islamic Educational, Scientific and Cultural Organization ISESCO-1427AH, 2006.

[5] T. Muneer, M. Asif, and S. Munawwar, "Sustainable production of solar electricity with particular reference to the Indian economy," Renewable and Sustainable Energy Reviews, vol. 9, no. 5, pp. 444-473, 2005.

[6] T. Chavda and N. Kumar, "Solar dryers for high value agro products at Spreri," in Proceedings of the International Solar Food Processing Conference, Indore, India, January 2009.

[7] D. E. Whitfield, "Solar dryer systems and the internet, important resources to improve food preparation," in Proceedings of the International Conference on Solar Cooking, Kimberly, South Africa, November 2000.

[8] H. Rahman, R. Karuppaiyan, K. Kishor, and R. Denzongpa, "Traditional practices of ginger cultivation in north east India," Indian Journal of Traditional Knowledge, vol. 8, no. 1, pp. 23-28, 2009.

[9] K. Singh, D. Tiroutchelvame, and S. Patel, "Drying characteristics of ginger flakes," in Proceedings of the 16th International Drying Symposium (IDS '08), pp. 1383-1386, Hydrabad, India, 2008.

[10] A. W. Deshmukh, M. N. Varma, C. K. Yoo, and K. L. Wasewar, "Effect of ethyl oleate pretreatment on drying of ginger: characteristics and mathematical modelling," Journal of Chemistry, vol. 2013, Article ID 890384, 6 pages, 2013.

[11] W. K. Lewis, “The rate of drying of solid materials," Journal of Industrial Engineering and Engineering Chemistry, vol. 13, pp. 427-432, 1921.

[12] G. Page, Factors influencing the maximum rates of air drying shelled corn in thin layers [M.S. thesis], Purdue University, West Lafayette, Ind, USA, 1949.

[13] S. M. Henderson and S. Pabis, "Grain drying theory I: temperature effect on drying coefficient," Journal of Agricultural Engineering Research, vol. 6, pp. 169-174, 1961.

[14] Z. Wang, J. Sun, X. Liao et al., "Mathematical modeling on hot air drying of thin layer apple pomace," Food Research International, vol. 40, no. 1, pp. 39-46, 2007.

[15] C. Y. Wang and R. P. Singh, "A single layer drying equation for rough rice," Paper No. 78-3001, American Society of Agricultural Engineers, St. Joseph, Mich, USA, 1978.

[16] A. W. Deshmukh, K. L. Wasewar, and M. N. Verma, "Solar drying of food materials as an alternative for energy crisis and environmental protection," International Journal of Chemical Sciences, vol. 9, no. 3, pp. 1175-1182, 2011.

[17] K. Ronah, C. Knali, J. Mailutha, and D. Shitanda, “Thin layer drying kinetics of amaranth grains in natural convection solar tent dryer," African Journal of Food Agricultural and Nutrition Development, vol. 10, no. 3, pp. 2218-2233, 2010.

[18] K. Sacilik, "Effect of drying methods on thin-layer drying characteristics of hull-less seed pumpkin (Cucurbita pepo L.)," Journal of Food Engineering, vol. 79, no. 1, pp. 23-30, 2007.

[19] M. Condorí, R. Echazú, and L. Saravia, "Solar drying of sweet pepper and garlic using the tunnel greenhouse drier," Renewable energy, vol. 22, no. 4, pp. 447-460, 2001.

[20] D. S. Sogi, U. S. Shivhare, S. K. Garg, and A. S. Bawa, "Water sorption isotherm and drying characteristics of tomato seeds," Biosystems Engineering, vol. 84, no. 3, pp. 297-301, 2003.

[21] C. Tiris, N. Ozbalta, M. Tiris, and I. Dincer, "Experimental testing of a new solar dryer," International Journal of Energy Research, vol. 18, no. 4, pp. 483-490, 1994.
[22] B. K. Bala, M. R. A. Mondol, B. K. Biswas, B. L. D. Chowdury, and S. Janjai, "Solar drying of pineapple using solar tunnel drier," Renewable Energy, vol. 28, no. 2, pp. 183-190, 2003.

[23] Y. M. Gallali, Y. S. Abujnah, and F. K. Bannani, "Preservation of fruits and vegetables using solar drier: a comparative study of natural and solar drying, III; chemical analysis and sensory evaluation data of the dried samples (grapes, figs, tomatoes and onions)," Renewable Energy, vol. 19, no. 1-2, pp. 203-212, 2000.

[24] E. K. Akpinar and Y. Bicer, "Modelling of thin layer drying kinetics of sour cherry in a solar dryer and under open sun," Journal of Scientific and Industrial Research, vol. 66, no. 9, pp. 764-771, 2007.

[25] A. Boubekri, H. Benmoussa, and D. Mennouche, "Solar drying kinetics of date palm fruits assuming a step-wise air temperature change," Journal of Engineering Science and Technology, vol. 4, no. 3, pp. 292-304, 2009.

[26] A. O. M. Akoy, M. A. Ismail, F. A. Ahmed, and W. Luecke, "Design and construction of solar dryer for mango slices," International Renewable Energy Review, vol. 4, no. 2, pp. 1-9, 2007.

[27] S. Phoeun, N. Phol, O. Romny, P. Pen, and S. Bun, "Solar dryers for small farmers and households in Cambodia," in Proceeding of the Regional Conference on Worlds Renewable Energy, pp. 1821, Jakarta, Indonesia, 2005.

[28] S. Ranganna, A Handbook of Analysis and Quality Control for Fruits and Vegetable Products, Tata McGraw-Hill, New Delhi, India, 2nd edition, 1995.

[29] R. Shalini, A. Ranjan, and N. Kumar, "Studies on the drying characteristics of apple pomace on tray dryer," in Proceedings of the 16th International Drying Symposium (IDS '08), pp. 16361640, Hydrabad, India, 2008.

[30] N. A. Akgun and I. Doymaz, "Modelling of olive cake thin-layer drying process," Journal of Food Engineering, vol. 68, no. 4, pp. 455-461, 2005.

[31] A. Steinfeld and I. Segal, "A simulation model for solar thin layer drying process," Drying Technology, vol. 4, no. 4, pp. 535-554, 1986.

[32] I. Doymaz, O. Gorel, and N. A. Akgun, "Drying characteristics of the solid by-product of olive oil extraction," Biosystems Engineering, vol. 88, no. 2, pp. 213-219, 2004.

[33] H. O. Menges and C. Ertekin, "Mathematical modeling of thin layer drying of golden apples," Journal of Food Engineering, vol. 77, no. 1, pp. 119-125, 2006.

[34] S. Phoungchandang and S. Saentaweesuk, "Effect of two stage, tray and heat pump assisted-dehumidified drying on drying characteristics and qualities of dried ginger," Food and Bioproducts Processing, vol. 89, no. 4, pp. 429-437, 2011.

[35] R. Abalone, A. Cassinera, A. Gastón, and M. A. Lara, "Some physical properties of amaranth seeds," Biosystems Engineering, vol. 89, no. 1, pp. 109-117, 2004.

[36] H. R. Gazor and S. Minaei, "Influence of temperature and air velocity on drying time and quality parameters of pistachio (Pistacia vera L.)," Drying Technology, vol. 23, no. 12, pp. 24632475, 2005.

[37] T. Garware, N. Sutar, and B. Thorat, "Drying of tomato using different drying methods: comparison of drying kinetics and rehydration ratio," in Proceedings of the 16th International Drying Symposium (IDS '2008), pp. 1427-1432, Hydrabad, India, 2008. 

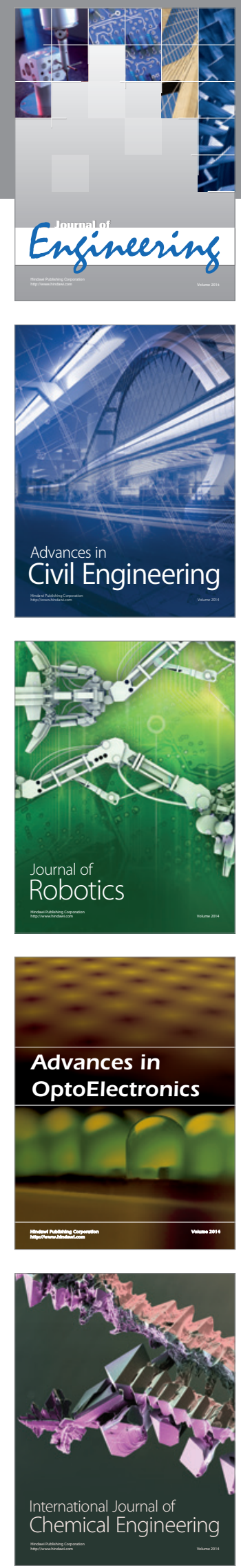

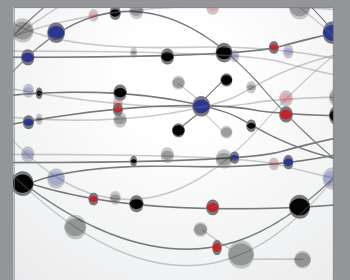

The Scientific World Journal
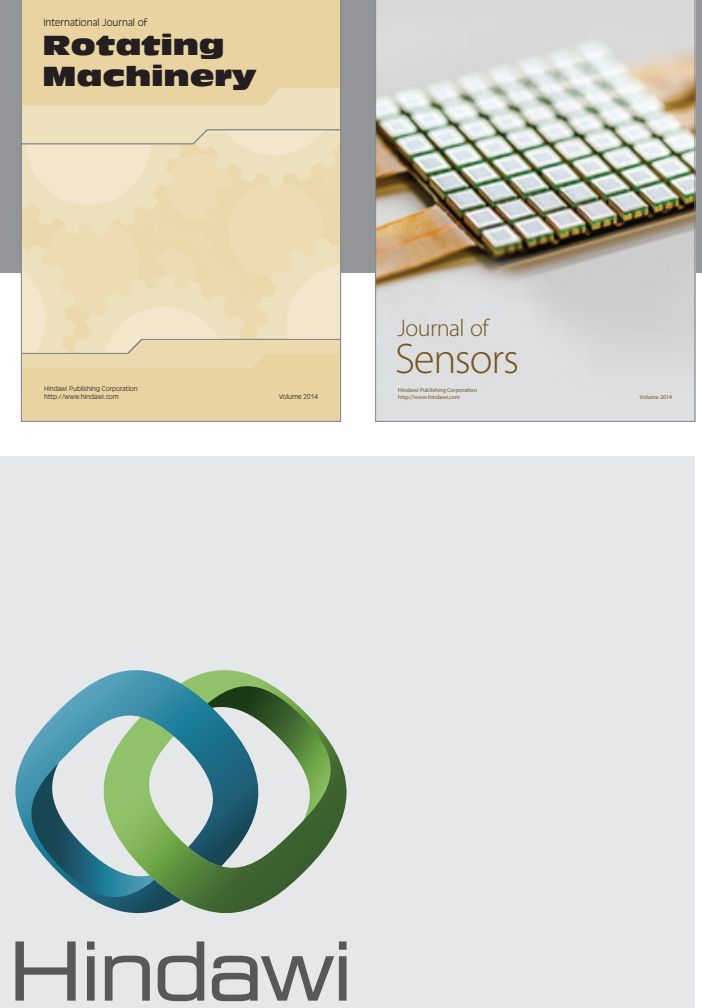

Submit your manuscripts at http://www.hindawi.com
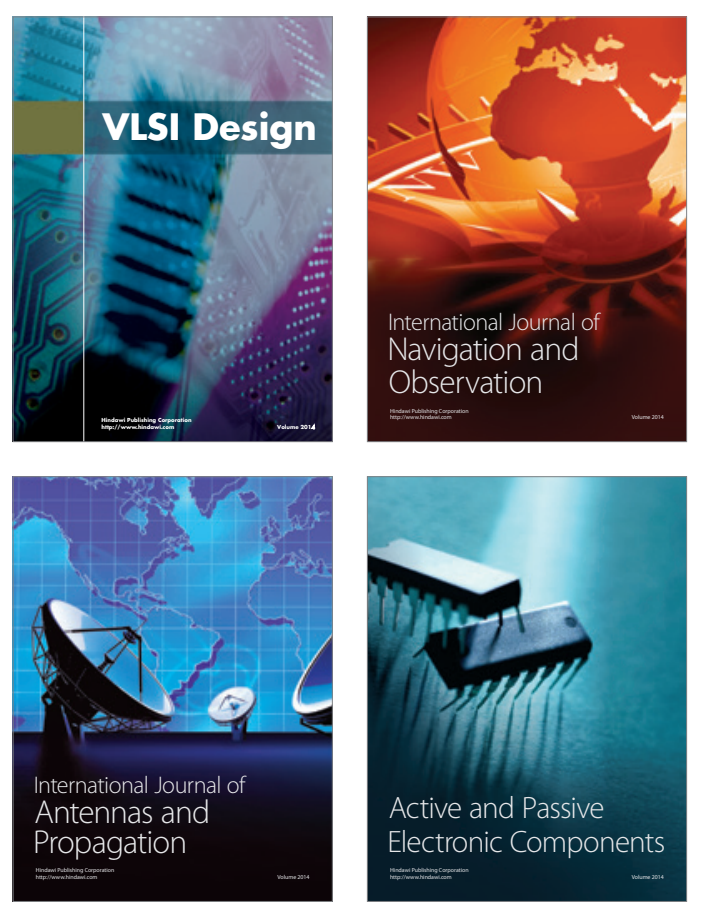
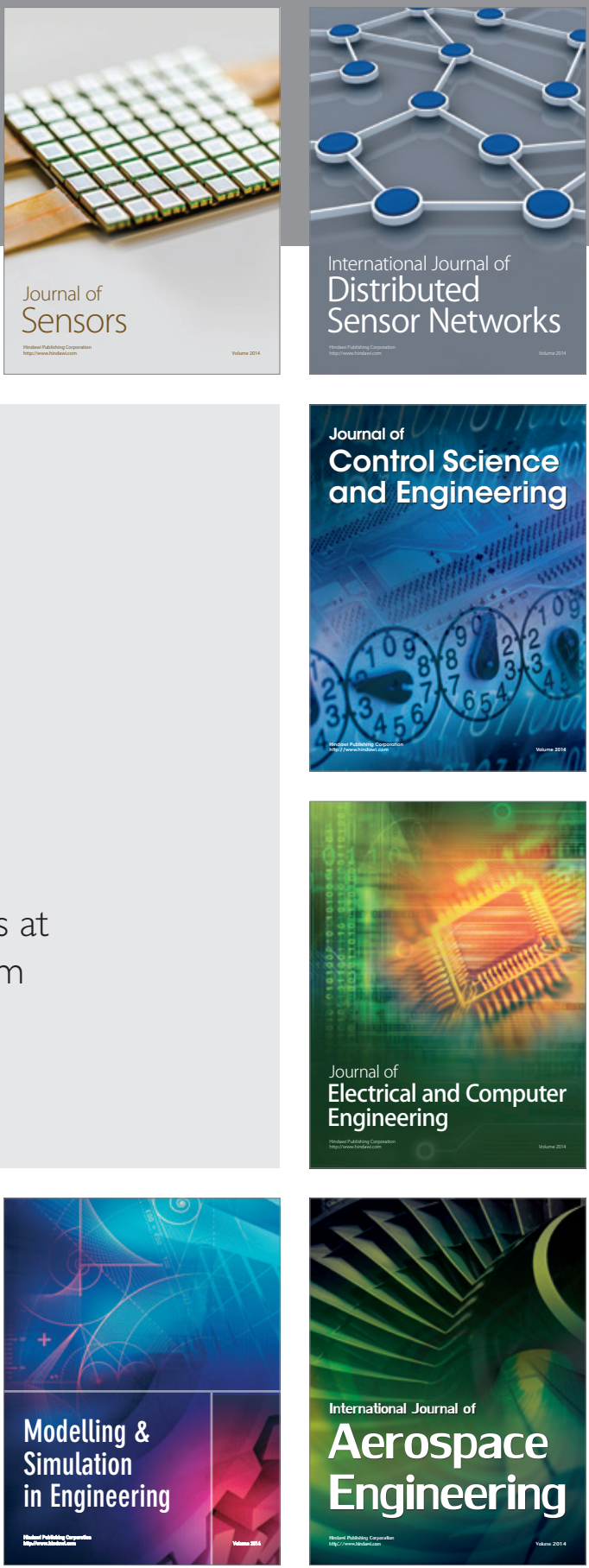

Journal of

Control Science

and Engineering
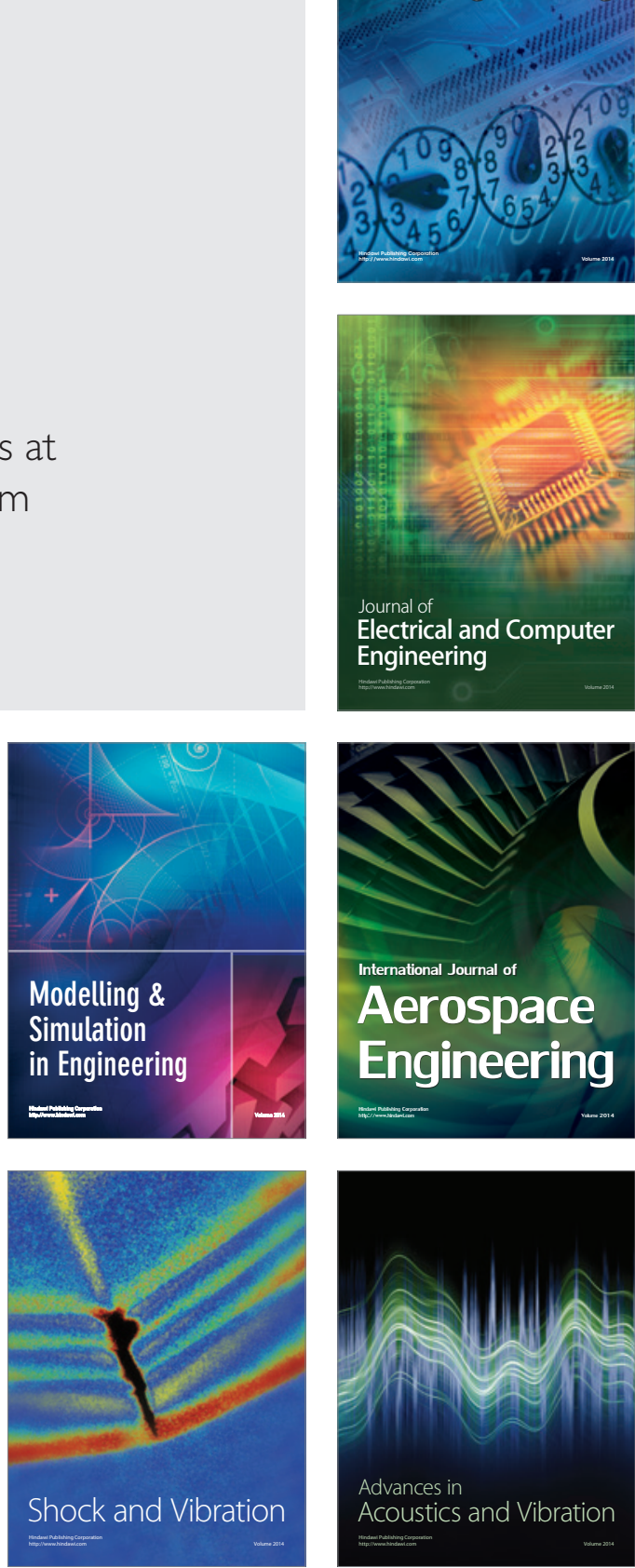